Gut, 1986, 27, $1181-1185$

\title{
Cholecystectomy and adenomatous polyps of the large bowel
}

\author{
KATHRYN J LLAMAS, LEILA G TORLACH, M WARD, AND C BAIN \\ From the Department of Gastroenterology, Royal Brisbane Hospital and Department of Social and \\ Preventive Medicine, University of Queensland, Queensland, Australia
}

SUMMARY Seventy two patients (39 women) with colonic adenomas were compared with 72 adenoma free controls (39 women) to investigate the possible association between previous cholecystectomy and the subsequent development of adenomas. Data were gathered retrospectively from medical records. Overall there was no significant association between colonic adenomas and previous cholecystectomy. When women are considered separately, however, eight cases and no controls had undergone cholecystectomy (odds ratio $\infty$ lower $95 \%$ confidence limits $1 \cdot 7, \mathrm{p}>0 \cdot 01$ ). No association between previous cholecystectomy and large bowel adenomas was found in men. Four of nine $(44.4 \%)$ women with right sided colonic adenomas had undergone previous cholecystectomy compared with only three of $23(13 \%)$ women with left sided adenomas.

Several recent studies ${ }^{1-6}$ have investigated the relationship between colonic cancer and previous cholecystectomy. Most have indicated an increased risk for women of developing right sided colonic cancer after cholecystectomy, ${ }^{12} 45$ but at least one study has shown a stronger association with rectal cancer, ${ }^{3}$ and some investigators have been unable to confirm any relationship. ${ }^{6}$

As colonic adenomatous polyps are generally thought to be precursors of colonic carcinoma, ${ }^{7-9}$ the purpose of this study was to determine whether there was any association between the presence of such lesions and previous cholecystectomy.

\section{Methods}

\section{PATIENTS}

The study population consisted of patients who underwent diagnostic colonoscopy during the years 1980 to 1982 in the Royal Brisbane Hospital, Department of Gastroenterology. There were 72 cases ( 39 women) for whom a matched control could be found. The patients were aged $30-85$ years, in whom one or more colonic or rectal polyps were

Address for correspondence: M Ward, Department of Gastroenterology. Royal Brisbane Hospital. Herston, Queensland 4(129. Australia.

Received for publication 6 February 1986. detected on colonoscopy, and who had no evidence of present or past large bowel cancer. The control group consisted of 72 men and women, in whom colonoscopy was normal, individually matched for age $( \pm 5$ years $)$ and sex.

The controls were selected consecutively from a colonoscopic diagnostic listing as having had a normal colonoscopy, with no past history of adenoma, colonic cancer, or other disease of the large bowel.

The proportions of patients excluded, because their charts were unavailable or contained insufficient data to determine cholecystectomy status, were comparable in the two groups $(22.8 \%$ adenoma patients and $29.4 \%$ controls).

Data were obtained by retrospective review of medical records and colonoscopy reports of adenoma and control patients, and were recorded on standard forms. Cholecystectomy status was determined by review of the past history and clinical examination sections of the medical records, as well as the surgeon's operation reports. Other gastrointestinal surgery, as well as the presence or absence of gall stones was also recorded. Histological type, size, number, and site of adenomas were noted from pathology and colonoscopy reports. Standard case control analyses (matched or unmatched as appropriate) were carried out using computation of odds ratio, $95 \%$ confidence limits and exact tests. ${ }^{10}$ 


\section{Results}

The average age at colonoscopy of adenoma patients was 57.3 years, and of controls was 55.6 years. Histological information was available in $54.2 \%$ of cases, the majority of adenomas being tubular or tubulovillous (Table 1). Thirty eight $(52.8 \%)$ of the patients had only a single adenoma, $32(44.4 \%)$ had between two and six adenomas, and two had more than six. The distribution of adenomas in the colon is shown in Table 2. Forty four $(61 \cdot 1 \%)$ of the

Table 1 Histological classification

\begin{tabular}{lcc}
\hline Histological type & Patients $(\%)$ & Patients (n) \\
\hline Villous adenoma & $1 \cdot 4$ & 1 \\
Tubulovillous adenoma & $18 \cdot 1$ & 13 \\
Tubular adenoma & $34 \cdot 7$ & 25 \\
No histology available & $45 \cdot 8$ & 33 \\
Total & $100 \cdot 0$ & 72 \\
\hline
\end{tabular}

Table 2 Distribution of adenomas in colon

\begin{tabular}{lcc}
\hline Site & Patients $(\%)$ & Patients $(n)$ \\
\hline Caccum & $9 \cdot 7$ & 7 \\
Ascending colon & $2 \cdot 8$ & 2 \\
Hepatic flexure & $0 \cdot 0$ & 0 \\
Transverse colon & $13 \cdot 9$ & 10 \\
Splenic flexure & $2 \cdot 8$ & 2 \\
Descending colon & $11 \cdot 1$ & 8 \\
Sigmoid colon & 66.7 & 48 \\
Rectum & 23.6 & 17 \\
\hline
\end{tabular}

NB: Percentage total exceeds $100 \%$ because some patients had adenomas in several sites. adenomas were less than $11 \mathrm{~mm}$ in diameter, eleven $(15.3 \%)$ were between 11 and $30 \mathrm{~mm}$ and two $(2 \cdot 8 \%)$ were greater than $30 \mathrm{~mm}$. No measurements were available in $15(20 \cdot 8 \%)$.

The matched pair analysis of cholecystectomy status is shown in Table 3. Overall, the proportion of adenoma patients having had a previous cholecystectomy was $11 \cdot 1 \%(8 / 72)$ compared with $2 \cdot 8 \%$ $(2 / 72)$ for controls. When the sexes are considered separately, however, some interesting differences emerge. Very few men had a history of cholecystectomy, and the $95 \%$ confidence interval for the odds ratio is, in consequence wide $(0 \cdot 0-5 \cdot 3)$. On the other hand, none of the 39 women controls had a history of cholecystectomy compared with eight of 39 women with adenomas (lower 95\% confidence bound $1.7(\mathrm{p}<0.01)$; matched analysis). The average time interval between cholecystectomy and colonoscopic diagnosis of adenomas in women was 4.5 years, range 7 months to 11 years.

Patients with adenomas in the caecum, ascending colon, hepatic flexure and/or transverse colon were classed as 'right sided adenoma patients', while those with adenomas in the splenic flexure, descending colon, sigmoid colon and/or rectum were classed as 'left sided adenoma patients'. The distribution in regard to cholecystectomy status in female patients is shown in Table 4 . Of women with right sided adenomas, $44 \%$ had undergone cholecystectomy, in contrast with only $12 \%$ of those with left sided lesions (odds ratio $6 \cdot 13,95 \%$ confidence limit $0 \cdot 7-53 \cdot 1$, $\mathrm{p}=0 \cdot 11$ ). Patients with adenomas on both sides of the colon were excluded from this analysis.

There were no associations of polyps with a variety of types of previous gastrointestinal surgery

Table 3 History of cholecystectomy in adenoma and control patients (matched analysis)

\begin{tabular}{|c|c|c|c|c|c|}
\hline & & \multicolumn{4}{|c|}{ Adenoma Patients } \\
\hline & & Positive & Negative & Total & $\begin{array}{l}95 \% \text { Confidence limits } \\
\text { for odds ratio }\end{array}$ \\
\hline \multicolumn{6}{|l|}{ 1. Men } \\
\hline \multirow{3}{*}{ Controls } & Positive & 0 & 2 & 2 & \\
\hline & Negative & 0 & 31 & 31 & \\
\hline & Total & 0 & 33 & 33 & \\
\hline \multicolumn{6}{|l|}{ 2. Women } \\
\hline \multirow[t]{3}{*}{ Controls } & Positive & 0 & 0 & 0 & \\
\hline & Negative & 8 & 31 & 39 & \\
\hline & Total & 8 & 31 & 39 & \\
\hline \multicolumn{6}{|c|}{ 3. Men and women } \\
\hline \multirow[t]{3}{*}{ Controls } & Positive & 0 & 2 & 2 & \\
\hline & Negative & 8 & 62 & 70 & $(0 \cdot 8-38 \cdot 7)$ \\
\hline & Total & 8 & 64 & 72 & \\
\hline
\end{tabular}

Note: 'Positive' and 'negative' refer to history of cholecystectomy. 
Table 4 Distribution of adenomas in female patients

\begin{tabular}{llcc}
\hline & \multicolumn{2}{l}{ Previous cholecystectomy } \\
\cline { 2 - 3 } Group & Yes & No & Total \\
\hline Right sided adenomas & 4 & 5 & 9 \\
Left sided adenomas & 3 & 23 & 26 \\
Totals & 7 & 28 & $35^{*}$ \\
\hline
\end{tabular}

${ }^{*}$ Four female patients with adenomas both sides are excluded from this Table.

(including appendicectomy, hernia repair, vagotomy, and surgery for inflammatory bowel disease).

\section{Discussion}

The results of this study suggest that cholecystectomy increases subsequent risk of developing adenomas of the large bowel in women, a finding which is congruent with increasing evidence of an association between previous cholecystectomy and the development of large bowel cancer. ${ }^{1-5}$ The data also suggest a tendency for adenomas to occur on the right side of the colon after cholecystectomy in women paralleling a similar right sided preponderance found for colon cancer after cholecystectomy. ${ }^{5}$ Vernick et $a l^{4}$ argue that the right side of the colon is most likely to be affected by the potential carcinogenic effect of bile salt metabolites.

The lack of any apparent association between cholecystectomy and the development of adenomas in men in this study may merely be because of their relative infrequency of cholecystectomy, but is also consistent with the sex distribution found in some studies of large bowel cancer. ${ }^{12}$ As such, it might reflect sex differences in bowel function, such as slower bowel transit time in women, ${ }^{11}$ or that women have a higher proportion of secondary bile acids in their bile than men. ${ }^{12}$

These results are consistent with bile salt/bacterial theory of the aetiology of colorectal cancer proposed by Hill, Drasar, and Williams. ${ }^{13}$ Cholecystectomy could predispose to the development of polyps of the large bowel and to cancer, by virtue of its effect on bile salt pool dynamics. Werner and de Heer ${ }^{14}$ have shown that cholecystectomy promotes colonic carcinogenesis induced by 1,2-dimethyl hydrazine $(\mathrm{DMH})$ in rats (although others have not reproduced this finding $\left.{ }^{15}\right)$. Cholecystectomy alters bile salt metabolism, and increases exposure of primary bile salts to colonic bacteria, thereby increasing the production of secondary bile salts, ${ }^{16-18}$ which have been implicated as colorectal carcinogens. They are found in raised concentrations in faecal specimens from subjects living in countries with a high incidence of colonic cancer. ${ }^{13}$ In a case control study, ${ }^{19}$ faecal concentrations of secondary bile salts were higher in patients with colon cancer and in patients with adenomatous polyps of the colon, than in patients with other digestive diseases and in normal controls; and laboratory studies ${ }^{20} 21$ have shown that the secondary bile acids, lithocholic acid, and deoxycholic acid, act as cocarcinogens in experimentally induced colonic cancer in animals.

Although the bile salt/bacterial theory of mechanism of development of colonic cancer and adenomas is an attractive one, there are several other explanations for the apparent association between previous cholecystectomy and development of colonic adenomas. Gall bladder disease itself, and not cholecystectomy per se, could lead to increased risk of cholecystectomy and of colonic adenomas and cancer. A recent study has examined the relationship between cholecystectomy, silent cholelithiasis and colonic adenomas. Mannes et $a l^{22}$ compared the prevalence of adenomatous polyps detected at colonoscopy in 333 patients who had previously undergone cholecystectomy with an asymptomatic group of 406 patients shown by ultrasonography to have gall stones in the gall bladder. There were no differences between these groups except among those aged 60-80 years. Patients who had undergone a cholecystectomy more than 10 years ago had significantly more adenomas (38.5\%) (and cancers) than either those having had their cholecystectomy less than 10 years ago $(21.8 \%)$ or a matched cholelithiasis group $(23 \cdot 7 \%)$. These results suggest that in the short term, cholecystectomy does not increase the rate of development of adenomas or cancers among those with gall bladder disease, but longer derangement of bile acid circulation may increase this risk among elderly patients. Additional support for a role for gall bladder disease per se comes from other research, ${ }^{2.3}$ which suggests that it is patients with gall stones, and not specifically those undergoing cholecystectomy, who have increased proportions of secondary bile acids. Findings in this area, however, are contradictory. ${ }^{17} 2.324$ Furthermore, although gall stones are much more common in women ${ }^{25}$ the sex difference in patients with colorectal cancer is only modest. ${ }^{326}$ On the other hand, it might be that previous gastrointestinal surgery somehow increases the risk of developing colonic adenomas and cancer. This seems unlikely, as previous work ${ }^{27}{ }^{28}$ has shown no increased risk of colonic cancer with various surgical procedures, and our data show no relationship with any procedure other than cholecystectomy.

Finally, in evaluating the validity of our findings, methodological weaknesses and possible sources of 
bias should be considered. Although the sample size is small, chance appears to be an unlikely explanation of the results among women. It is possible that biases associated with retrospective review of hospital records could produce a spurious association between previous cholecystectomy and development of large bowel polyps. The higher cholecystectomy prevalence in a population sample of women of similar age to our own controls $(11 \cdot 6 \%$ compared with $0 \%$, unpublished observation, Bain 1983), suggests that there may well have been some selection bias. Even using the higher estimate, however, female adenoma patients in this study remain approximately twice as likely as the general population to have had a cholecystectomy. Undertaking colonoscopy on all patients ensured accurate ascertainment of adenoma status, and the use of standard abstraction forms and procedures makes bias with respect to noting past cholecystectomy unlikely. Further, assuming any misclassification of cholecystectomy status is random could only mean that the real association is stronger than that observed. Moreover, the fact that such a relationship is consistent with the growing body of evidence that supports the bile salt/bacterial theory of development of colonic neoplasms makes it less likely that these findings are spurious.

In conclusion, the present study suggests that cholecystectomy may be a predisposing factor in the development of adenomas of the large bowel in women, particularly of the right colon. A larger study involving interview of patients at the time of colonoscopy is in progress in an attempt to investigate this issue further.

We gratefully acknowledge the assistance of $\mathrm{Dr} \mathrm{V}$ Siskind (Department of Social and Preventive Medicine, University of Queensland.

\section{References}

1 Linos DA, Beard CM, O'Fallon WM, Dockerty MB, Beart RW, Kurland LT. Cholecystectomy and carcinoma of the colon. Lancet 1981; 2: 379-81.

2 Anonymous. Large bowel cancer after cholecystectomy. Lancet 1981; 2: 562-63.

3 Turnbull PRG, Smith AH, Isbister WH. Cholecystectomy and cancer of the large bowel. Br J Surg 1981; 68: 551-53.

4 Vernick LJ, Kuller LH, Lohsoonthorn P, Rycheck RR, Redmond CK. Relationship between cholecystectomy and ascending colon cancer. Cancer 1980; 45: 392-95.

5 Vernick LJ, Kuller LH. Cholecystectomy and rightsided colon cancer: an epidemiological study. Lancet 1981; 2: 381-83.
6 Adami H, Meirik O, Gustavsson S, Nyren O, Krusemo $\mathrm{U}$. Colorectal cancer after cholecystectomy: absence of risk increase within 11-14 years. Gastroenterology 1983; 85: 859-65.

7 Hawley PR. Polyps and carcinoma of the large bowel. Med Int (Australian edition) 1982; 14: 626-30.

8 Morson BC, Bussey HJR. Current problems in surgery. Chicago: Year Book Medical Publishers, 1970: 19-31.

9 Morson B. The polyp-cancer sequence in the large bowel. Proc R Soc Med 1974; 67: 451-57.

10 Breslow N, Day N. Statistical methods in cancer research. I. The analysis of case-control studies. IARC Scientific Publications, No. 32. Lyon: IARC, 1980.

11 Gear JSS, Brodribb AJM, Ware A, Mann JI. Fibre and bowel transit times. Br J Nutr 1981; 45: 77-82.

12 Fisher MM, Yousef IM. Sex differences in the bile acid composition of human bile: studies in patients with and without gallstones. Can Med Assoc J 1973; 109: 190-93.

13 Hill MJ, Drasar BS, Williams REO. Faecal bile acids and clostridia in patients with cancer of the large bowel. Lancet 1975; 1: 535-39.

14 Werner B, de Heer K. Effects of cholecystectomy on colon carcinogenesis. In Grundmann E, ed. Colon cancer (Cancer Campaign. Vol. 2). Stuttgart and New York: Fischer, 1978; 103-11.

15 Schattenkerk ME, Li AKC, Jeppsson BW, et al. Cholecystectomy has no influence on frequency of chemically induced colonic cancer in mice. Br J Cancer 1980; 42: 791-93.

16 Malagelada JR, Go VLW, Summerskill WHJ, Gamble WS. Bile acid secretion and biliary bile acid composition altered by cholecystectomy. Am J Dig Dis 1973; 18: $455-59$.

17 Pomare EW, Heaton KW. The effect of cholecystectomy on bile salt metabolism. Gut 1973; 14: 753-62.

18 Hepner GW, Hofmann AF, Malagelada JR, Szczepanik PA, Klein PD. Increased bacterial degradation of bile acids in cholecystectomized patients. Gastroenterology 1974; 66: 556-64.

19 Reddy BS, Wynder EL. Metabolic epidemiology of colon cancer: fecal bile acids and neutral sterols in colon cancer patients and patients with adenomatous polyps. Cancer 1977; 39: 2533-39.

20 Chomchai C, Bhadrachari N, Nigro ND. The effect of bile on the induction of experimental intestinal tumours in rats. Dis Colon Rectum 1974; 17: 310-12.

21 Reddy BS, Watanabe K, Weisburger JH, Wynder EL. Promoting effect of bile acids in colon carcinogenesis in germ free and conventional F233 rats. Cancer Res 1977; 37: 3238-42.

22 Mannes AC, Weinzier IM, Stellaard F, Thieme C, Wiebecke B, Paumgartner G. Adenomas of the large intestine after cholecystectomy. Gut 1984; 25: 863-6.

23 van der Linden W, Katzenstein B, Nakayama F. The possible carcinogenic effect of cholecystectomy: no postoperative increase in the proportion of secondary bile acids. Cancer 1983; 52: 1265-68.

24 Doouss TW, Castleden WM. Gallstones and carcinoma of the large bowel. NZ Med J 1973; 77: 162-65.

25 Macleod J, ed. Davidson's principals and practice of medicine. New York: Churchill Livingstone, 1981; 413-17. 
26 McMichael AJ, Potter JD. Reproduction, endogenous and exogenous sex hormones, and colon cancer: a review and hypothesis. J Natl Cancer Inst 1980; 65: 1201-07.

27 Hyams L, Wynder EL. Appendectomy and cancer risk: an epidemiological evaluation. J Chron Dis 1968; 21: 391-415.

28 Wynder EL, Kajitani T, Isnikawa S, Dodo H, Takano A. Environmental factors of cancer of the colon and rectum. Cancer 1969; 23: 1210-20.

\section{Forthcoming Scientific Meetings of the British Society of Gastroenterology}

SPRING 1987 - No meeting

AUTUMN 1987 - 15-18 September Jubilee Meeting at the Institute of Education, London

SPRING 1988 - 23-25 March

University of Leicester

AUTUMN $1988-13-16$ September
University of Sheffield

For details of registration please contact: The Administrative Secretary, BSG, 3 St Andrew's Place, Regent's Park, London NW1 4LB.

Tel: 01-387-3534 (International 44-1-387-3534) 